\title{
The Effects of Seasonal Thermal Loads at Expansion Joints Locations in Arabic Area Buildings
}

\author{
Ikhlass Sydnaoui, Roslli Bin Noor Mohamed, Mariyana Aida Binti Ab.Kadi
}

\begin{abstract}
Concrete buildings are subjected to fluctuation in seasonal temperature loads between summer and winter in the Arabic area. The long-term effects of such temperatures on concrete buildings, accompanied by the variation in ambient temperatures, induce thermal displacements and forces in concrete structures. The thermal forces and displacements influence over time the safety and functionality of the premises, while many cracks are imposed. This study investigates the effective response of reinforced concrete buildings considering thermal seasonal load fluctuations and long-term effects of creep and shrinkage in the Arabic area. In recent decades, structures without joints have become necessary. In order to use this option, super-long structures with a length of more than 60 meters must takes into account the impact of thermal load fluctuations in their design. A proper methodology must be provided to define the greatest permitted distance between expansion joints in addition to a clear process for buildings thermal study. Different approaches are provided by researchers, each methodology provides different values for required joints spacing considering different aspects in design. In this paper, I shall try to present three methods with a comparison study for considered aspects and gaps for each method analysis to propose the most appropriate methodology to support engineers in calculating the maximum allowed spacing between expansion joints.
\end{abstract}

Keywords: Fluctuation, Long-Term; Expansion Joints; Thermally

\section{INTRODUCTION}

Shrinkage and creep of concrete are influenced by environmental aspects such as the weather relative humidity and seasonal temperature variations [1]. Temperature variations creep and shrinkage directly affects the life span of concrete buildings, the hydration of cement at high values of temperature imposes changes in the cement properties. The deformation of creep increases at $50 \mathrm{C}^{\circ}$ to be three times more than strains at $\left(20-25 \mathrm{C}^{\circ}\right)$. The temperature range of fifty to eighty degrees causes the largest value of creep [1]. The superposition of humidity, creep, shrinkage and temperature variations have a similar type of stresses and strains [2]. The concrete deformation is the superposition of shrinkage strain, creep strain, cracking and thermal strain. The longer-term effects of temperature are imposed due to the largest variation

Revised Manuscript Received on July 22, 2019

* Correspondence Author

Ikhlass Sydnaoui, Designer structural engineer*, Faculty of Civil Engineering, University Teknologi Malaysia, Johor Bahru, Malaysia. Email: Ikhlass.sydnaoui@musanada.com

Dr. Roslli Bin Noor Mohamed, Faculty of Civil Engineering, University Teknologi Malaysia, Johor Bahru, Malaysia. Email: roslli@utm.my

Dr. Mariyana Aida Binti Ab. Kadir, Faculty of Civil Engineering, University Teknologi Malaysia, Johor Bahru, Malaysia. Email: mariyanaida@utm.my of winter and summer temperature, the most important value is the maximum variation in temperature. The changes in concrete Volume related to temperature variations and ambient environment moisture have to be analyzed within the structural calculations of the reinforced concrete buildings whereas the building movements and the forces related to changes in building volume are related to the size of the building segments without separation joints [3]. The contraction and the expansion of concrete is the summation of the variations in the volume of concrete under seasonal temperature variations. The critical response of super long premises is related to the decrease in ambient environment temperature accompanied by shrinkage of concrete [4]. These premises are subjected to high stresses and deformations under thermal loads. To eliminate this issue, structural engineers provide expansion joints. Expansion joints are used to decrease the deformations of thermal loads and correlated forces between adjacent segments of the building. Expansion joints decrease the width of contraction cracks hence these joints are protected by thermal insulation, so they can be considered as insulation and expansion joints[5]. Expansion joints allow for the contraction and the expansion of buildings under the variation of thermal loads changes within acceptable limits of stresses and deformations [5-6].

\section{METHODOLOGY}

\section{A.Used Methods}

The designer engineer defines the exact location of thermal separations considering the variation in the building volume related to thermal effects. Some methods were provided by SCSE Committee in 1974 for expansion joints locations and conditions. These methods are used in the Arabic area to define joints spacing. The location of expansion joints is from the roof slab down to footings. It is allowed to provide one footing for separated segments of the building [6]. Adding contraction and expansion joints separates the structures into parts, thereby decreasing the stresses, steel, reinforcement, the used sections of concrete, and the extent of deformation imposed by ambient humidity or changes in temperature (Aziz and Azeem, 2018 [5]. Elongation (T) in a building subjected to temperature can be defined from this 
equation $\mathrm{T}=\mathrm{a} * \mathrm{~L} *(\operatorname{tmax}-\mathrm{tmin})$ whereas(a) is the expansion thermal coefficient of concrete, (L) is the building length and (tmax-tmin) is the difference in temperature loads between summer and winter [3].

In the Arabic area, the spacing between expansion joints under thermal loads could be calculated considering different methods such the analytical method, Martin and Acosta which is applicable under specific conditions, and the National academy of sciences.

\section{B. The method of Martin and Acosta:}

It is commonly used for one-story concrete construction with the same spacing between columns. There is an equation that calculates the expansion joint spacing $(\mathrm{Lj})$ between adjacent parts of the building segments from Figure (1) in feet

$$
\mathrm{Lj}=112000 /(\mathrm{R} . \Delta \mathrm{T})
$$

whereas $\mathrm{R}$ is related to the stiffness of used columns and beams

$$
R=\frac{144 \cdot I c(1+r)}{h^{2}(1+2 r)}
$$

$r$ is related to columns and beams stiffness $r=K c / K b$ while

$\Delta T$ is the summation of daily temperature changes and

shrinkage, $\Delta T=\frac{2}{3}(T \max -T \min )+T s$

whereas $T$ s is $-17 C^{\circ}=-30 F^{\circ}$ for drying shrinkage consideration.

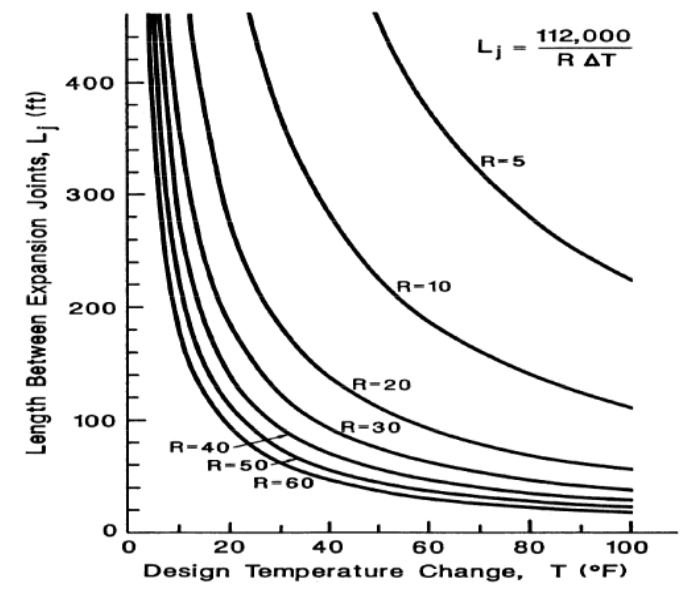

Fig. 1. Expansion joints separation for one-story concrete frame building versus variation in daily temperature [3].

This method ignored many factors which affect stresses in concrete buildings such as: the used concrete properties, the columns support conditions, the used span between columns, the shape of the building, the slabs thicknesses and the life span of the building, which are important factors with direct impact at the building long term stresses. The question here: is it logic to use same joints spacing for concrete frame buildings regardless these mentioned points?

\section{C.National academy of sciences Method}

Federal agencies used Figure (2) below to define the expansion joints spacing with respect to temperature changes. It is rules of thumb and expert engineers' consensus without analyzing or calculations. Figure (2) shows that: the increment in variation between maximum or minimum annual temperature and the mean temperature at pouring period will decrease the expansion joints spacing and the length of related building segments. The greatest permitted spacing between joints is inversally correlated to annual temperature diversity. The lowest and highest values for spacing between joints are $200 \mathrm{ft}(61 \mathrm{~m})$ and $600 \mathrm{ft}$ $(182,8 \mathrm{~m})$ respectively, as shown in Figure (2). It is engineers' consent for all different materials without engineering substantiations [7].

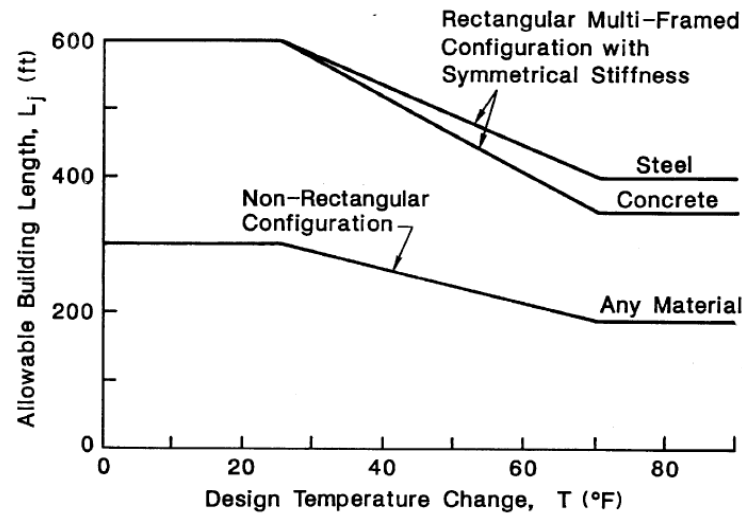

Fig. 2.The allowable spacing between building segments in feet [3].

The national academy of sciences considered the curve in figure 2 for the allowable building segments between expansion joints. A comparison study was initiated by Public Buildings Administrations between the theoretical effect of temperature changes on two frames buildings and the actual strains observed in one year. This comparison led to developing figure (3) below by the SCSE 2000 committee [6].

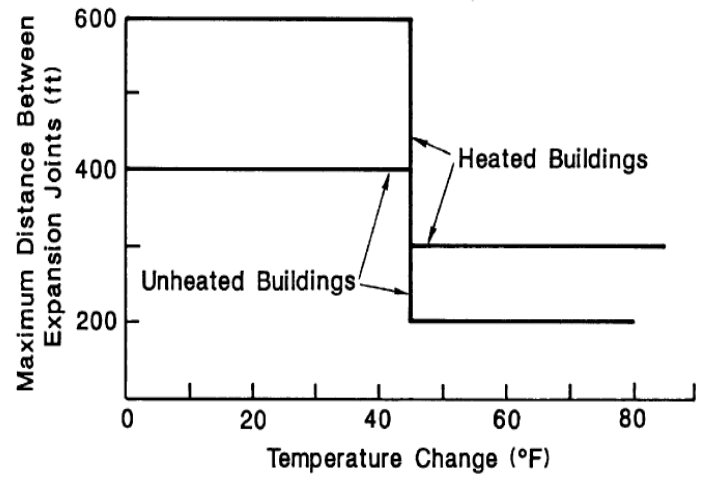

Fig. 3.Expansion joint spaces as SCSE committee 2000. [3-6]

Based on the findings of the Public Buildings Administration, the SCSE Committee (2000) analysed the strains of expansion joints in existing buildings. They found out that: hinged columns force reactions at its base are lower than fixed columns values. The imposed thermal stresses are proportional to the structural element's sizes. The width of the expansion joint will increase for hinged columns premises [3-9]. 
The thermal deformations at upper levels above the 1st slab for hinged and fixed columns supports are symmetrical. Some conditions are provided such as: reducing the allowable limit of the joint spacing by $15 \%$ for buildings with fixed conditions at column supports. The updated function in Figure (3) considers heated buildings with columns supports conditions at their base. Modification factors are required for buildings subjected to air conditions heating or cooling. Increasing the allowable joints spacing by $15 \%$ for heated buildings. Reducing the allowable segments' length by $33 \%$ for non-heated premises. It is noted that this method ignored many factors such as the impact of the used concrete properties, the columns height, shrinkage and creep effects, the used span between columns, the shape of used buildings and stories number in addition to the design life span of the building.

\section{The analytical method (SCSE Committee, 2000).}

The unique modern shape of buildings, displacements, and forces imposed by temperature fluctuation fluctuation makes it impractical to define the spacing between joints by using the aforementioned methods. In these cases, an accurate structural analysis must be followed whilst considering changes in temperature and after reaching a compromise between the serviceability and capacity of buildings against the imposed forces and their capability to withstand thermal displacements. Computer analysis is essential to conduct the required analysis for stresses and deformations and to help engineers to define the capacities of the buildings [6]. These aforementioned methods cannot be applied in super-long, modern buildings for thermal analysis. In order to understand the imposed stress and correlated displacements, the sequence of construction, the sizes of elements, and material properties should be considered in the computer calculation. Finite element programs such as SAP and ETABS are widely used to study the thermal fluctuation and shrinkage [7].

\section{RESULT AND DISCUSSION}

For super long buildings, finite element programs are required to evaluate the induced displacements, forces, and stress of these phenomena, taking into account the importance of the used mesh to divide the structural elements, the accuracy of applied loads, and material properties [8], as well as the boundary condition of the model at results precisely. The maximum allowed slab length providing expansion joints is calculated taking into account the National Academy of Sciences and Martin and Acosta methodologies [3].and analytical finite elements 'method. The aforementioned methods are specified in American standards and permitted in the Arabic area and correlated municipalities. Same methods will be used in this paper to conduct a comparison study in results and allowed joints spacing. Following are the variables that will be considered in this study, columns are square shape, the dimensions of the columns are $800 \mathrm{~mm}^{2}$ with beam span $10 \mathrm{~m}$, two columns supports conditions are considered fixed and hinged. The design temperature maximum daily variation is:

whereas $\mathrm{Ts}$ is $-17\left(\mathrm{C}^{\mathrm{o}}\right)=-30\left(\mathrm{~F}^{\circ}\right)$ for drying shrinkage consideration. The design temperature with maximum daily variation is $9-43=-34\left(C^{\circ}\right)$ as shown in Fig. (1). while Ts is 17(C), the total variation will be

$$
\boldsymbol{\Delta T}=\frac{2}{3}(\operatorname{Tmax}-\mathrm{Tmin})+T s=22.6+17=39.7 \mathrm{C}^{\circ} .
$$

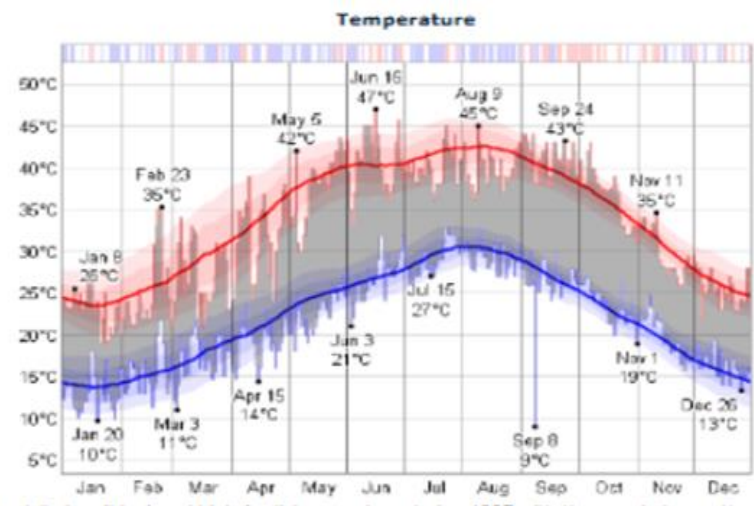

Fig. 4. Fluctuations in environmental temperature reported in 1997 (A.D.I.A, 2015) [11]

A. Martin and Acosta- method (A)

Tables (I) and (II) clarify the concrete frame buildings stiffness properties and the maximum allowed spacing between expansion joints $\mathrm{Lj}$ for concrete frame buildings as per Martin and Acosta method for slab thickness $30 \mathrm{~cm}$ for columns heights $3 \mathrm{~m}$ and $6 \mathrm{~m}$. All element sizes are presented in $\mathrm{cm}$ and inch. The maximum allowed spacing between expansion joints is $83.95 \mathrm{~m}$ and $167.9 \mathrm{~m}$ for both columns' heights $3 \mathrm{~m}$ and $6 \mathrm{~m}$ respectively regardless of the slab thickness value whereas $\mathrm{Lj}$ max for buildings with storey height of three meters is $1111 \mathrm{~h} / \boldsymbol{\Delta T} .=1111 \times 3 / 39.7=83.95 \mathrm{~m}$, while for storeys with column height of $6 \mathrm{~m}$, it rises to be $167.9 \mathrm{~m}$ taking into account same formula.

Table-I: The columns and beams stiffness values for concrete building with $30 \mathrm{~cm}$ slab thickness

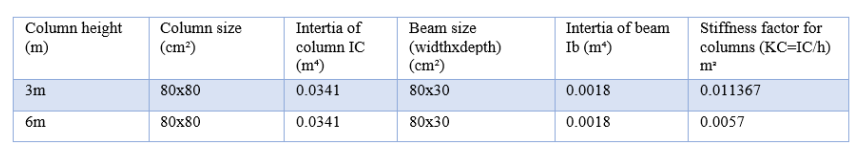

Table- II: The allowed expansion joint spacing in the meter for concrete frame building with slab thickness $30 \mathrm{~cm}$ and columns height $3 \mathrm{~m}$ and $6 \mathrm{~m}$.

\begin{tabular}{|l|l|l|l|l|l|}
\hline $\begin{array}{l}\text { Column height } \\
(\mathrm{m})\end{array}$ & $\begin{array}{l}\text { Stiffness factor for } \\
\text { beam }(\mathrm{Kb}=\mathrm{b} / \mathrm{b} / \mathrm{l})\left(\mathrm{m}^{\mathrm{s}}\right)\end{array}$ & $\mathrm{r}$ & $\begin{array}{l}\mathrm{R} \\
\left(\mathrm{m}^{2}\right)\end{array}$ & $\begin{array}{l}\mathrm{Lj} \\
(\mathrm{m})\end{array}$ & $\begin{array}{l}\mathrm{Lj} \max \\
(\mathrm{m})\end{array}$ \\
\hline $3 \mathrm{~m}$ & 0.00018 & 63.15 & 0.281 & 1.12 & 83.95 \\
\hline $6 \mathrm{~m}$ & 0.00018 & 31.67 & 0.0692 & 4.5 & 167.9 \\
\hline
\end{tabular}

Tables (Ш) and (IV) clarify the concrete frame buildings stiffness properties and the maximum allowed spacing between expansion joints $\mathrm{Lj}$ for concrete frame buildings as per Martin and Acosta method for slab thickness $40 \mathrm{~cm}$ for columns heights $3 \mathrm{~m}$ and $6 \mathrm{~m}$. All element sizes are presented in $\mathrm{cm}$. whereas $\mathrm{Lj}$ max for buildings with storey height of three meters is $1111 \mathrm{~h} / \boldsymbol{\Delta T} .=1111 \times 3 / 39.7=83.95 \mathrm{~m}$, while for storeys with column height of $6 \mathrm{~m}$, it rises to be $167.9 \mathrm{~m}$ taking into account same formula.

Table Ш: The columns and beams stiffness values for concrete frame building with slab thickness $40 \mathrm{~cm}$.

\begin{tabular}{|l|l|l|l|l|l|}
\hline $\begin{array}{l}\text { Column } \\
\text { height } \\
(\mathrm{m})\end{array}$ & $\begin{array}{l}\text { Column size } \\
\left(\mathrm{cm}^{2}\right)\end{array}$ & $\begin{array}{l}\text { Intertia of } \\
\text { column IC } \\
\left(\mathrm{m}^{+}\right)\end{array}$ & $\begin{array}{l}\text { Beam size } \\
(\text { widthdepth) } \\
\left(\mathrm{cm}^{2}\right)\end{array}$ & $\begin{array}{l}\text { Intertia of } \\
\text { beam IB } \\
\left(\mathrm{m}^{4}\right)\end{array}$ & $\begin{array}{l}\text { Stiffness factor } \\
\text { for columns } \\
(\mathrm{KC}=\mathrm{IC} / \mathrm{h})\left(\mathrm{m}^{\mathrm{s}}\right)\end{array}$ \\
\hline $3 \mathrm{~m}$ & $80 \times 80$ & 0.0341 & $80 \times 40$ & 0.00427 & 0.01136 \\
\hline $6 \mathrm{~m}$ & $80 \times 80$ & 0.0341 & $80 \times 40$ & 0.00427 & 0.0057 \\
\hline
\end{tabular}


Table -IV: The allowed expansion joint spacing in the meter for concrete frame building with slab thickness $40 \mathrm{~cm}$ and columns height $3 \mathrm{~m}$ and $6 \mathrm{~m}$.

\begin{tabular}{|l|l|l|l|l|l|}
\hline $\begin{array}{l}\text { Column height } \\
(\mathrm{m})\end{array}$ & $\begin{array}{l}\text { Stiffness factor for } \\
\text { beam }(\mathrm{Kb}=\mathrm{Ib} / \mathrm{l})\left(\mathrm{m}^{\mathrm{s}}\right)\end{array}$ & $\mathrm{r}$ & $\begin{array}{l}\mathrm{R} \\
\left(\mathrm{m}^{2}\right)\end{array}$ & $\begin{array}{l}\mathrm{Lj} \\
(\mathrm{m})\end{array}$ & $\begin{array}{l}\mathrm{Lj} \max \\
(\mathrm{m})\end{array}$ \\
\hline $3 \mathrm{~m}$ & 0.000427 & 26.6 & 0.2778 & 1.11 & 83.95 \\
\hline $6 \mathrm{~m}$ & 0.000427 & 13.35 & 0.07066 & 4.36 & 167.91 \\
\hline
\end{tabular}

B. National academy of sciences- $\operatorname{method}(B)$ :

$\Delta \mathrm{T}$ is the largest from $\Delta \mathrm{T}=\mathrm{Tw}-\mathrm{Tm}$, or $\Delta \mathrm{T}=\mathrm{Tm}-\mathrm{Tc}$, Where, $\mathrm{Tm}$ is the temperature normally noticed within the construction period. Tw is the high temperature which is just exceeded for a ratio of one percent within the summer. Tc is the low temperature exceeded ninety -nine percent within the winter season (ACI Committee 224.3R, 2001) and Tm is the temperature of weather at construction. Historical weather for 1991 (Figure 5), the highest difference in its daily temperature is noticed in January and June. The assumption of structure works begins in Jun in June at $47 \mathrm{C}^{\circ}$, the lowest temperature is in January with a Temperature of $6 \mathrm{C}^{\circ}$. Therefore, the difference is $47-6=41 \mathrm{C}^{\circ}, 99 \%(41)=40 \mathrm{C}^{\circ}$

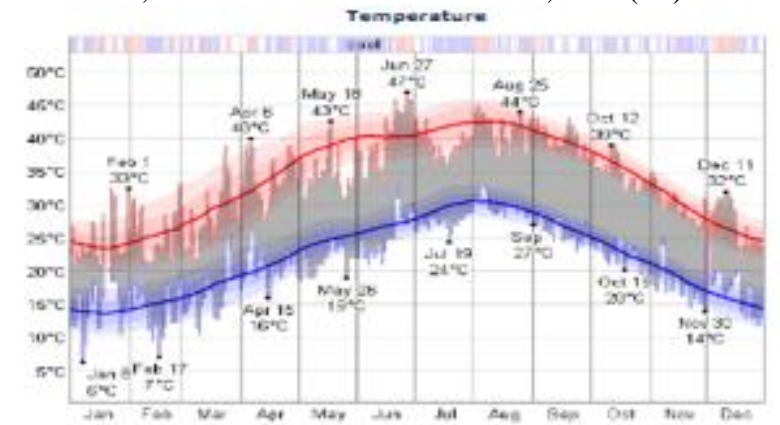

Fig. 5 Fluctuations in environmental temperature reported in 1991 [11].

Using Fig 3, the greatest permitted distance between joints for temperature fluctuation of $40 \mathrm{C}^{\circ}=104^{\circ} \mathrm{F}$ is 200 feet $=60.96$ $\mathrm{m}$ for unheated buildings with hinged supports. While this distance is reduced to $51.816 \mathrm{~m}$ for premises with fixed supports As a conclusion of these methods results, table (V) below clarifies the maximum allowed spacing between expansion joints of adjacent building segments considering the empirical approaches Martin and Acosta and the National Academy of sciences. There is a clear variation in allowed spacing values. For columns with a height of $3 \mathrm{~m}$, the National academy of sciences allowed spacing between expansion joints $60.96 \mathrm{~m}$ and $51.816 \mathrm{~m}$ are lesser than Martin and Acosta method value $83.95 \mathrm{~m}$ for hinged and fixed columns support consequently, while Martin and Acosta method values increased to $167.9 \mathrm{~m}$ for columns with height $6 \mathrm{~m}$ with constant values for National academy of sciences method which ignored the effect of story height. While Martin and Acosta's process neglected support type and inertia of slabs and took into account the height of storey and stiffness of correlated beams and columns, as well as environment fluctuation and shrinkage effects. while the National academy of sciences took into account the column supports type, and neglected columns stiffness and height of storey. It ignored all structural elements stiffness and don't have a clear limitation for the maximum allowable lateral deflection.

Table-V: Maximum permitted distances (in $\mathrm{m}$ ) between joints according to the empirical approaches

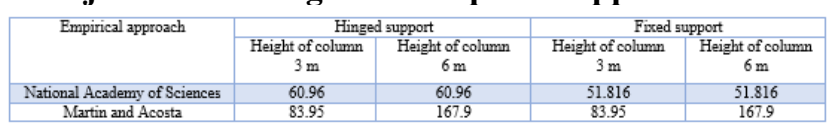

\section{The analytical method by finite elements models}

144 finite element Etabs-three diminutions models are generated. The concrete strength is $40 \mathrm{~N} / \mathrm{mm} 2$ hence this value is almost used for concrete buildings in The Arabic area. two different support conditions are considered, the fixed and the hinged columns support. The variables considered in ETABS models are: the length of the models varies from $400 \mathrm{~m}$ to $50 \mathrm{~m}$ with $20 \mathrm{~m}$ difference, the height of columns are $6 \mathrm{~m}$ and $3 \mathrm{~m}$, the thickness of s;abs are $300 \mathrm{~mm}$ and $400 \mathrm{~mm}$. the width of the slab is constant as : $50 \mathrm{~m}$. The coefficient of thermal expansion of concrete value $9.9 \times 10$ $6 \mathrm{CC}^{\circ}$ as determined by various tests on unrestrained concrete samples with different reinforcement compositions, cement types, and aggregate sizes $[10,12]$ Modulus of elasticity $(\mathrm{E})=$ $30000 \mathrm{MPa}, \mathrm{Ec}=4750 \sqrt{\mathrm{fc}}$ [8], Poisson ratio for concrete was considered $=0.2$. The temperature value is the greates observed in both methodologies to be taken into account in finite element analysis. Figure 6 shows the slab and columns of a typical model. Figure 7 presents deformations under thermal loads for the slab. Maximum deformations parallel to slab length are recognized at slabs edges, so columns at slab edges are subjected to the largest displacements and they are the critical columns under thermal loads, so they will be considered in the study

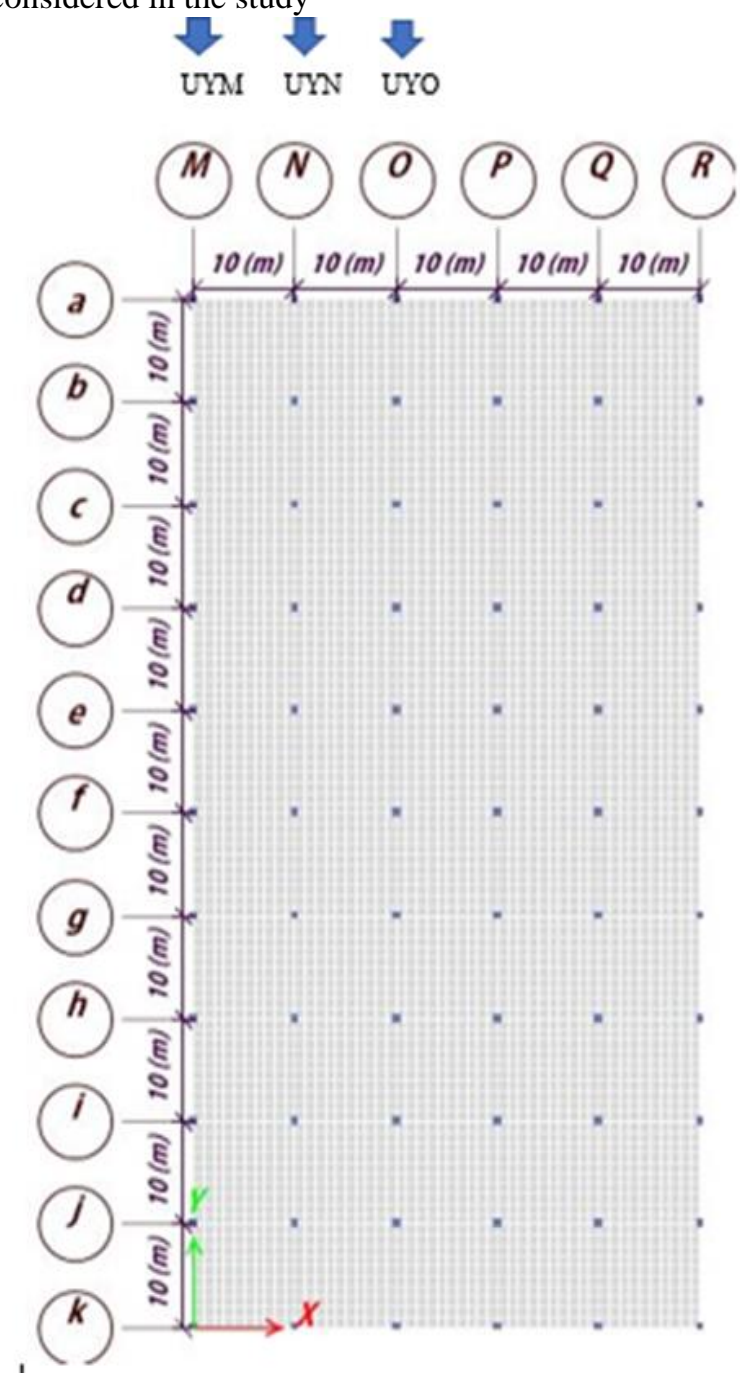

Fig. 6. The slab and columns of a typical model 


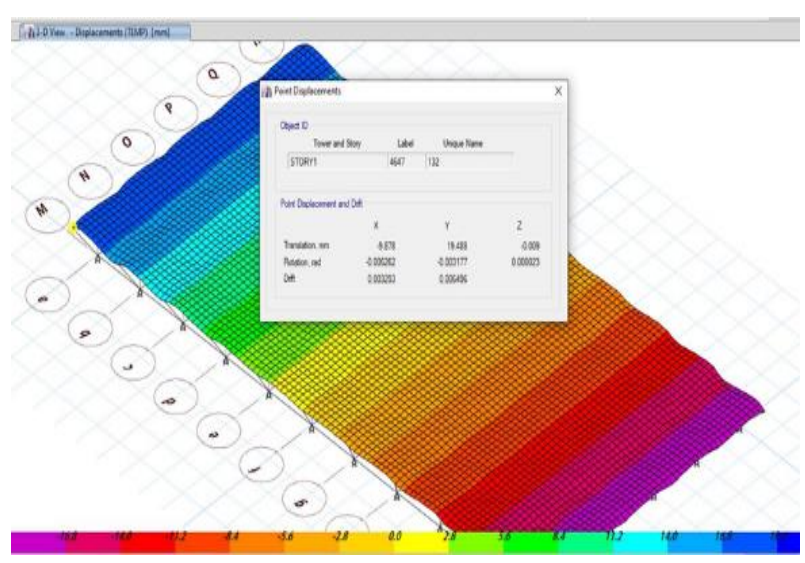

Fig. 7. Contours of slabs deformations under thermal loads.

The maximum deformations for hinged columns seem identical at the slab edge as shown in figure 5. the highest observations of thermal displacements for hinged and fixed model supports are mainly clustered in column $\mathrm{O}$ at the center of slab edge. Accordingly, the analysis of column displacements will concentrate on column $\mathrm{O}$, which has experienced the greatest displacements. Figure 8 clarify that columns $\mathrm{M}, \mathrm{N}$ and $\mathrm{O}$ thermal displacements for models with lengths lesser than $180 \mathrm{~m}$ are identical with thermal displacements of unconstrained structures [3,12] than other analysed slabs. It supports the structural engineer's calculations and analysis for deformations values.

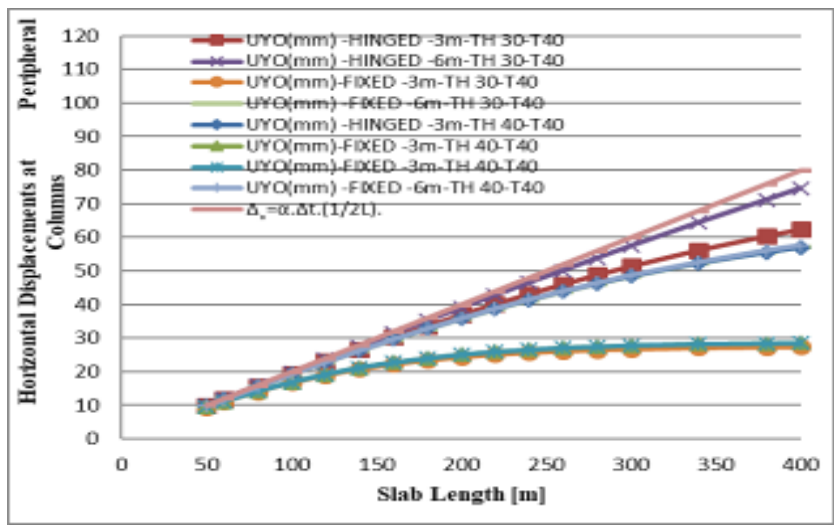

Fig. 8. Horizontal deformations at peripheral columns

Figure 8 presents that the thermal displacement (UY) of column $\mathrm{O}$ grows in proportion to the height of the column and the length of the slab. The findings of the analysis also show that employing thick slabs slightly decreases thermal displacements for models with hinged column supports with 6 $\mathrm{m}$ column height and super-long slabs for fixed conditions. overall, all thermal displacements of analysed structural are lesser than the those of unconstrained buildings, it is the half displacements of slab edge induced in unconstrained structures [3].

To minimize the damages at external walls, ACI codes formulated an equation for computing the maximum permissible lateral displacement. This limit is directly proportional to column or storey height and must not exceed $\frac{H}{180}$. For models with $3 \mathrm{~m}$ column height, this limit is $\frac{3000}{180}=$ $16.67 \mathrm{~mm}$. Meanwhile, for models with $6 \mathrm{~m}$ column height, the limit is $\frac{H}{180}=\frac{6000}{180}=33.33 \mathrm{~mm}$, both limits are shown in figures 9 and 10 .

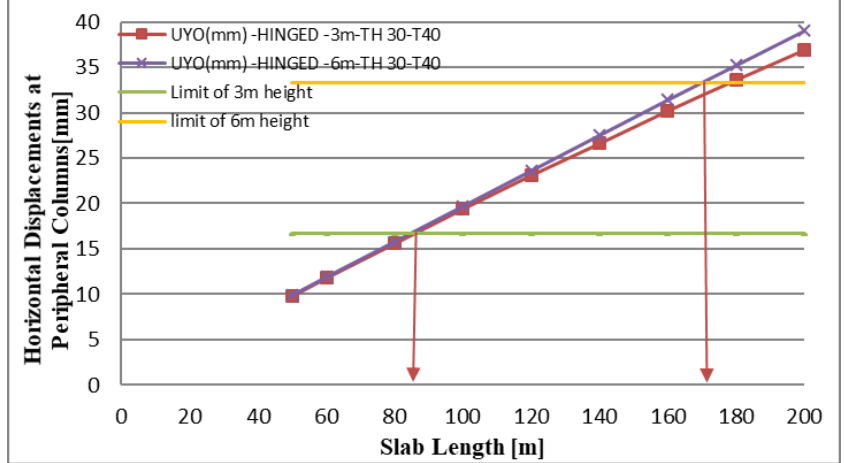

Fig. 9. Maximum spacing between joints for models with $30 \mathrm{~cm}$ slab thickness

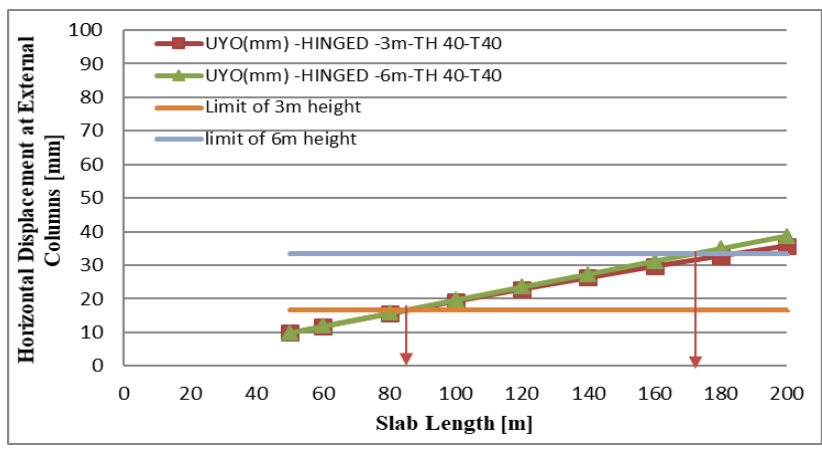

Fig. 10. Maximum spacing between joints for models with $40 \mathrm{~cm}$ slab thickness

An expansion joint needs to be installed for slabs under the fixed column support condition and with lengths exceeding $101 \mathrm{~m}$ for both slab thicknesses and $3 \mathrm{~m}$ column height models, this distance increase significantly to $184 \mathrm{~m}$ for similar models with a column height $6 \mathrm{~m}$. Meanwhile, the limit for slabs under the hinged column support conditions and $3 \mathrm{~m}$ column height is $89 \mathrm{~m}$ because the deformations under this condition are greater than those under the fixed column support condition as shown in Table VI. Therefore, intersection points of deformation curves and limit lines of $3 \mathrm{~m}$ models have less slab length. Those buildings with $6 \mathrm{~m}$ column height have a deformation limit of up to $33.3 \mathrm{~mm}$. According to Figures 7 and 8, the allowable spacing between joints with $30 \mathrm{~cm}$ slab thickness and fixed column support is $187.72 \mathrm{~m}$. However, when the slab thickness increases to 40 $\mathrm{cm}$, this spacing decrease to $184.2 \mathrm{~m}$. Meanwhile, the maximum allowable spacing for models with $6 \mathrm{~m}$ column height and hinged column support is reduced to $176.5 \mathrm{~m}$ because this column support condition has a higher thermal deformation than the fixed one. Therefore, the intersection points of deformation curves with the limit line of $6 \mathrm{~m}$ models will have lesser slab lengths between expansion joints. Table V1 presents the greatest permitted distance between building joints that the difference in slab thickness has a minor impact on the permitted distance. Therefore, the allowable spacings for hinged models with $30 \mathrm{~cm}$ and $40 \mathrm{~cm}$ slab thicknesses and $3 \mathrm{~m}$ column heights are almost similar as $89.023 \mathrm{~m}$ and 89.02 $\mathrm{m}$, respectively. While this difference increased to $8 \mathrm{~m}$ for hinged models with $6 \mathrm{~m}$ column height. Similarly, the allowable spacings for fixed models with $30 \mathrm{~cm}$ and $40 \mathrm{~cm}$ slab thicknesses and $3 \mathrm{~m}$ column heights are $107.8 \mathrm{~m}$ and $101.14 \mathrm{~m}$, respectively. 
In sum, the difference in the allowable spacing for both slab thicknesses is less than $8 \mathrm{~m}$, while both column height and support condition have major impacts on maximum spacings between expansion joints ranging from $89.02 \mathrm{~m}$ to $187.7 \mathrm{~m}$

Table- VI: The greatest permitted distance of Joints

\begin{tabular}{|c|c|c|c|}
\hline Slab thickness. $(\mathrm{cm})$ az & Column height.(m) $x$ & Hinged columns\% & Fixed columng: \\
\hline $30 \%$ & $3 \mathrm{~m}$ & $89.023 \mathrm{mw}$ & $107.8 \mathrm{~m}$ \\
\hline $30 \%$ & $6 \mathrm{~m}$ & $176.5 \mathrm{~mm}$ & $187.72 \mathrm{~m}$ \\
\hline $40 x$ & $3 m$ & $89.02 \mathrm{mx}$ & $101.14 \mathrm{mo}$ \\
\hline $40=0$ & $6 m a$ & $168.8 \mathrm{~mm}$ & $184.2 \mathrm{ma}$ \\
\hline
\end{tabular}

\section{CONCLUSION}

The thermal displacements at external columns of the same storey level are not similar, and such variance is more obvious in models with fixed supports. Given that, axial stiffness is directly proportional to slab thickness and area. Therefore, thicker slabs have higher stiffness and lower thermal displacements. The distance between super building joints are defined by using all methods, including the approaches of Martin and Acosta and the National Academy of Sciences and NTDP models. In sum, Martin and Acosta method returned a constant allowable spacing for all models with respect to column height. Meanwhile, the approach of the National Academy of Sciences obtains an allowable spacing of 60.96 $\mathrm{m}$ for hinged models, which is $15 \%$ higher than that for fixed models regardless of the variance of columns height or slab thickness. For buildings with $3 \mathrm{~m}$ column heights, the allowable spacings computed by using the approach of NTDP finite element method are more than those obtained by other methods. Meanwhile, the allowable spacings computed by NTDP for hinged model conditions with $30 \mathrm{~cm}$ and $40 \mathrm{~cm}$ slab thicknesses are close to the results of Martin and Acosta. Regarding models with $6 \mathrm{~m}$ column height, the NTDP joint spacings exceed those of the empirical methods. Also, a clear variance in the allowable spacings is observed for all models as per the empirical methods.

\section{Table-VII: The maximum allowed spacing between} Joints

\begin{tabular}{|c|c|c|c|c|c|c|c|c|}
\hline \multirow[t]{3}{*}{ Method } & \multicolumn{4}{|c|}{ Hight of column $(3 \mathrm{~m})$} & \multicolumn{4}{|c|}{ Hight of column $(6 \mathrm{~m})$} \\
\hline & \multicolumn{2}{|c|}{$\begin{array}{l}\text { Thickness of slab } \\
(300 \mathrm{~mm})\end{array}$} & \multicolumn{2}{|c|}{$\begin{array}{l}\text { Thickness of slab } \\
(400 \mathrm{~mm})\end{array}$} & \multicolumn{2}{|c|}{$\begin{array}{l}\text { Thickness of slab } \\
(300 \mathrm{~mm})\end{array}$} & \multicolumn{2}{|c|}{$\begin{array}{l}\text { Thickness of slab } \\
(400 \mathrm{~mm})\end{array}$} \\
\hline & Hinged & Fixed & Hinged & Fixed & Hinged & Fixed & Hinged & Fixed \\
\hline Martin : & 83.95 & 83.95 & 83.95 & 83.95 & 167.9 & 167.9 & 167.9 & 167.9 \\
\hline $\begin{array}{l}\text { National Academy of } \\
\text { Sciences }\end{array}$ & 60.96 & 51.816 & 60.96 & 51.816 & 60.96 & 51.816 & 60.96 & 51.816 \\
\hline NTDP (F.E.M) & 89.02 & 107.8 & 89.02 & 101.14 & 176.5 & 187.72 & 168.8 & 184.2 \\
\hline
\end{tabular}

As shown in the tableVII, each method obtains unique values for the maximum allowable spacing between expansion joints. Specifically, the approach of Martin and Acosta returned a constant allowable spacing of $3 \mathrm{~m}(83.95 \mathrm{~m}$ spacing) and $6 \mathrm{~m}$ (167.9 m spacing) for all models. These spacings are proportional to column height. Meanwhile, the approach of the National Academy of Sciences obtains an allowable spacing of $60.96 \mathrm{~m}$ for hinged models, which is $15 \%$ higher than that for fixed models. For buildings with 3 m column heights, the allowable spacings computed by using the approach of National Academy of Sciences are less than those obtained by other methods, whereas the approach of the NTDP finite element method always returns the highest spacings for models with $3 \mathrm{~m}$ column heights. Meanwhile, the allowable spacings computed by NTDP for fixed model conditions with $30 \mathrm{~cm}$ and $40 \mathrm{~cm}$ slab thicknesses are 107.8 $\mathrm{m}$ and $101.14 \mathrm{~m}$, respectively which are close to the results of Martin and A costa than those of the National Academy of Science. The NTDP results for models with $6 \mathrm{~m}$ column height exceed the results of the empirical methods. These empirical methods also show a clear variance in their allowable spacings for models with $6 \mathrm{~m}$ columns height.

\section{ACKNOWLEDGMENT}

The authors gratefully acknowledge the support of this research by UTM, Faculty of Civil Engineering UTM.

\section{REFERENCES}

1. Bazant, Z. and Baweja, S. (2000). 'Creep and shrinkage prediction model for analysis and design of concrete structures: model B3', ACI special publication creep and Shrinkage of Concrete.), pp 1-73.

2. Bijon, A., and Sarkar, T. (2017). "Study of temperature load on structure's', Imperialh Journal of Interdisciplinary Research (IJIR), 3, pp 1110-1114.

3. ACI Committee 224.3R. 2001. Joints in concrete construction. 1-43.

4. Ahmed, K. (2011). 'Temperature Effects in Multistory Building', Journal of Engineering Sciences, Assiut University, 39, pp 249-267.

5. Aziz, J., and Azeem, M. (2018). 'Comparative study of a R.C.C structure for the elimination of expansion joint subjected to temperature stresses', Journal of Engineering Research and Application, (8), pp 73-81.

6. SCSE Committee, 2000. Expansion joints in buildings 1974, Technical report No 65: 1-43.

7. Pooja, M., and Karthiyaini, S. (2017). 'Investigation of flat slab structures with and without expansion joints for thermal stresses', International Journal of Civil Engineering and Technology,8, pp 12871295.

8. Hamza, O., S. Attard, D. and Gatt, R. (2015). and Abejide, O. (2016) 'Effectveness of expansion joints provision for temperature and load in steel structures', International Journal of Reasearch in Engineering AND Applied Sciences, 6, pp 209-223..

9. Hamza, O., S. Attard, D. and Gatt, R. (2015). and Abejide, O. (2016). 'Effectveness of expansion joints provision for temperature and load in steel structures', International Journal of Reasearch in Engineering AND Applied Sciences, 6, pp 209-223.

10. Aboumoussa, W., and Iskandar, M. Thermal movement in concrete: case study of multi-story underground car park. Materials in civil engineering, 2012. 109- M07: 63-70.

11. DAILY TEMPERATURE, https://weatherspark.com/history.

12. Havel, A. Anthony,S.and Archilla, R. (2015). 'Coefficient of Thermal Expansion of Concrete Mixes in Hawaii: Determination and Implications for Concrete Pavement', Design. Journal of Materials in Civil Engineering, 27, pp 56-78.

13. ACI Committee 318. 2014. Buildings code requirements for structural concrete. 1-479.

\section{AUTHORS PROFILE}

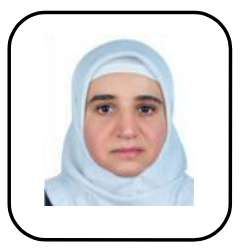

Ikhlass Sydnaoui: Preparing for PHD degree at UTM university in structural -civil engineering, final viva is at 2020

Master's Degree in structural - building Engineering, (Structure Section), Alhosn University2015, GPA 3.97/4

Preparing for Master's Degree in Civil Engineering, (Structure Section), Damascus University

High diploma (2 years with 10 structural subjects and thesis) in structural engineering design, Damascus University, 82\% (2001) Bachelor's Degree in structural/ civil Engineering, (structure Section), Damascus University, (1999)

20 years' experience as structural designer engineer and then senior structural reviewer and designer

5 years as lecturer in Damascus university for civil engineering college

A competent result-driven senior structural engineering professional with 20 years of experience, including 15 years international experience in the UAE in the Middle East, mainly in areas of managing, reviewing \& structural designing engineering for many projects constructed as per recognized American codes, British standards and local authority's requirements.

A good team player, with ability to lead the team to deliver results and successfully meet strict deadlines. 
Possess quick decision-making abilities and leadership qualities, with ability to work efficiently in demanding work environments to meet deadlines.

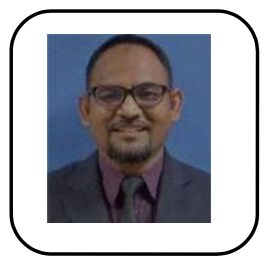

Dr. Roslli Bin Noor Mohamed | Right alert (DS52)

Second Vice-Chair of the School Chair Faculty of Engineering

School of Civil Engineering.

Department of Structure \& Materials Faculty of Civil Engineering University of Technology Malaysia Skudai, email roslli@utm.my

Academic coordinator at post graduate (course work) with continuous following up with post graduate students.

Senior Lecturer, Universiti Teknologi Malaysia With different onferences and publications such as:

Shear strength of short recess precast dapped end beams made

of steel fibre self-compacting concrete

RN Mohamed, KS Elliott

33rd Conference on Our World in Concrete \& Structures, Singapore

Concrete

The effects of inclined shear reinforcement in reinforced concrete beam, NF Zamri, RN Mohamed, NHA Khalid, KY Chiat Malaysian Journal of Civil Engineering 30 (1)

Bond stress in grouted spiral connectors

ABA Rahman, M Mahdinezhad, IS Ibrahim, RN Mohamed Jurnal Teknologi 77 (16)

Shear capacity of composite slab reinforced with steel fibre concrete topping

IS Ibrahim, MBC Bakar, NN Sarbini, RN Mohamed Malaysian Journal of Civil Engineering 23 (1)

Properties of Lightweight Concrete Using Palm Oil Clinker in Prestressed

Concrete Beam

W Omar, RN Mohamed Universiti Teknologi Malaysia.

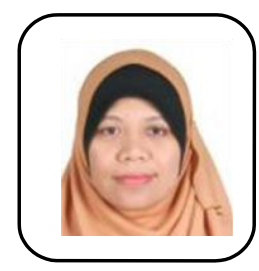

Dr. Mariyana Aida Ab Kadir is a Senior Lecturer at the Structure and Materials Department, Faculty of Civil Engineering, Universiti Teknologi Malaysia (UTM). She is the Research Fellow at the Institute of Noise and Vibration (INV) and Engineering Seismology and Earthquake Engineering Research (eSEER). After completing her secondary education at Mara Junior Science Collage, she pursue her B.Eng in Civil Engineering at UTM with First Class Honours and Chancellor's Award in 2005. She was awarded with Erasmus Mundus Scholarship for M.Sc in Earthquake Engineering and Seismology Engineering at two universities; University of Pavia, Italy and Université Joseph Fourier, Grenoble France before completing a $\mathrm{PhD}$ at University of Edinburgh, Scotland United Kingdom in Structural Seismic and Fire Engineering. Dr. Mariyana research interest focuses on the vulnerability of structures expose to risk of hazards for earthquake and fire, soil-structure interaction, input ground motion for structural design, new structural system for earthquake and fire, and durability of concrete materials. She particularly focuses on the earthquake and fire performance of concrete structure. 